\title{
Espaçamentos em Elvira Vigna
}

\author{
Leonardo Tonus ${ }^{*}$
}

Os três volumes de Tempo e narrativa de Paul Ricoeur apresentam uma teoria complexa acerca das possíveis relações entre narrativa e temporalidade (RICOEUR, 1984). Segundo o filósofo francês, entre a atividade de contar uma história e o caráter temporal da experiência humana existe uma correlação que não é puramente acidental. Pelo contrário, a narratividade assegura, em sua opinião, a superação das aporias relativas tanto à percepção quanto à compreensão do tempo. Se este postulado parece-nos promissor no que tange à uma leitura da literatura em geral, ele assume um papel fulcral no âmbito da modernidade, nomeadamente, ao eleger a temporalidade como parâmetro estético e crítico. As obras de Proust, Joyce, Virginia Woolf e Thomas Mann, bem como os trabalhos dos críticos Pouillon, Genette e Sternerberg constituem uma prova emblemática da importância conferida às categorias temporais no universo da criação e da crítica literária dos últimos anos. É, por exemplo, a partir das categorias temporais que Genette (1972) repensa em grande parte as configurações e os dispositivos narrativos, e, em particular, o estatuto do narrador: a sua inserção ou não na diégese em função do posicionamento do narrador no eixo temporal (narração anterior, simultânea ou posterior), seu protagonismo ou não (homodiegese/heterodigese) em função do regime temporal dos verbos.

Segundo o crítico francês Michel Collot, a era das temporalidades e dos modelos linguísticos deixaram de existir. Ao longo dos anos 80 observa-se na literatura e na crítica uma promoção do espaço enquanto resposta ao declínio de um modelo centrado numa visão linear e progressista da história. Esta nova orientação epistemológica teria afetado todos os campos da ciências humanas ao apontar, nomeadamente, para uma inversão das hierarquias entre tempo e espaço (COLLOT, 2014). Curiosamente, a maior parte dos estudos de poética narrativa continua a ignorar a categoria espacial em suas análises limitando-se, na maioria dos casos, a estudála somente em função da lógica descritiva. Com efeito, que lugar ocupa hoje o espaço no conjunto da inteligência narrativa, e em particular, na determinação do estatuto do narrador? O presente trabalho tem por objetivo indagar como a literatura brasileira contemporânea tem pensado e reavaliado a espacilidade de seus narradores. A partir do conceito de "espaçamento" (ou da "espaciação") veremos de que maneira o distanciamento emocional e cognitivo imposto às vozes autorais nos romances $O$ que deu para fazer em matéria de história de amor (2012) e Por es-

\footnotetext{
Professor da Universidade Paris-Sorbonne - Paris IV, França. E-mail: leotonusbr@hotmail.com.
} 
crito (2014) da escritora Elvira Vigna colocam em xeque a artificialidade da ficção, apontando ao mesmo tempo, para uma dimensão ética do gesto literário.

Ao refletir acerca da especificidade dos narradores no conjunto de sua obra, e mais precisamento no romance $O$ que deu para fazer em história de amor a escritora Elvira Vigna em entrevista concedida ao Blog Etudes Lusophones, em 2011, comentava:

Nesta ocasião, estou frente à seguinte dificuldade. Meu último texto ficcional, o "Nada a dizer", teve um narrador problematizado de forma radical. Depois de uma longa fila de narradores que acham necessário: 1) avisar que mentem ao contar a história; 2) que declaram não ter ideia de como a história acaba, ensaiando inclusive várias hipóteses para ela; 3) que não têm nome ou vários nomes diferentes; 4) no Nada a dizer, o narrador simplesmente não conta a história. Todo o livro é uma problematização de seu papel como narrador, e a história a ser contada - a de um assassinato - não é contada. Agora, trato de pensar um próximo narrador a partir da base comum a todos eles, e que é espacial antes de ser temporal (VIGNA, 2011).

A atribuição de uma certa espacialidade ao narrador decorre de exigências impostas pela própria autora após confrontrar-se com uma série de dilemas na elaboração de seus romances. O primeiro dentre eles diz respeito à fricção existente entre realidade e ficção que permeia boa parte de seus textos. A noção de "experiência” subjaz a prática escritural de Elvira Vigna que busca, pela revalorização do banal, romper com os procedimentos artísticos de espetacularização. Pela proximidade que implica o banal, trata-se de assegurar o reconhecimento das singularidades pela presença de um narrador que, segundo a autora, se assume "de carne e osso" e que por isso mesmo conserva um distanciamento - emocional, cognitivo - em relação ao narrado. Elvira Vigna afirma:

Como o que conto é sempre o vivido, tal distância também será, ao mesmo tempo, uma distância de mim (VignA, 2011).

O segundo dilema manifesta-se pelo emprego recorrente de estratégias semântico-narrativas capazes, segundo a autora, de romper com estruturas enquadradas e elaboradas a partir de um ethos "pré-fabricado" e não em função da visão de um cotidiano pessoal, próximo, visto ou vivenciado pelo sujeito de enunciação. Segundo a autora, ao se beneficiarem da distância que mantém com o seu assunto, as narrativas espetacularizadas de nossa contemporaneidade, não expõem leitores e narradores à experiência do diverso. Pelo contrário, elas limitam-se a "re-presentações" pasteurizadas que refutam o pensamento e um processo artístico aberto ao questionamento e à transformação. Os procedimentos de autocorreção de que se vale a autora no conjunto de sua obra corroboram este posicionamento. Eles asseguram a presença de narradores que assumem sua 
fragilidade através de uma prática escritural que, ao se construir nas tergiversências das vozes narrativas e das percepções individualizadas do leitor, se fragiliza permanecendo sempre aberta e em movimento.

Como sublinha o crítico Anderson da Mata (2012), é na narração da tentativa de escrever uma história que se sustenta o romance $O$ que deu para fazer em história de amor de Elvira Vigna. Nele, o leitor é confrontado, desde o título e incipit, a uma voz que não somente desacredita na sua capacidade de contar uma história de amor, mas expõe publicamente a sua incapacidade de evocar qualquer tipo de história elaborada nos modelos narrativos tradicionais. A descrença do ato narrativo é concomitante nos romances da autora à emergência de um discurso metaficcional preterível que tende a multiplicar as estruturas autocorretivas.

Chega um cheiro de cigarro da mesa ao lado. Aspiro. Não fumo, nunca fumei, se me pergutarem, não gosto de cigarro, não pergutam, já sabem. No entanto, gosto. E podia parar por aqui. Por que nisto que penso. Nessas histórias que parecem uma coisa e são outra. [...] eu vou dizer que não quero. E no entanto, quero. E quero porque preciso da história. Precisamos. Digo, não eu e Roger. Apenas. Mas todos. [...] e é disso que eu quero/não quero (VIGNA, 2012, p. 11).

Ao temer as armadilhas da espetacularização e seus silencimentos a narradora de $O$ que deu para fazer em história de amor trilha ao longo do incipit novos caminhos para sua história, o que a leva a buscar um tom mais adequado ao texto, a confrontar suas personagens a novas situações e a inserir sua história em diferentes épocas e períodos. Se num primeiro momento, a década de 6o lhe parece mais apropriada à história, uma década que segundo a voz enunciadora explicaria "sempre muita coisa (os petrodólores, o início da ditadura militar, e sobretudo a boa trepada no chuveiro)" (VIGNA, 2012, p. 14-15), ela evoca, em seguida, a possibilidade de inseri-la no pós-guerra dos anos 40, 50, 60 ou 7o. Finalmente ela acaba por optar pela década de 50, mas mediante um contraponto temporal que não abandona o presente de enunciação a partir do qual ela fala. Entre o que a narradora se propõe a relatar e não o faz, entre o que ela poderia fazer e acaba por modificar, multiplicam-se ao longo do incipt procedimentos de reescrita, de reajustamento e de correção. Mal uma frase é proferida que logo ela já se vê desdobrada, explicada e reinterpretada a exaustão. $\mathrm{O}$ incipt do romance articula-se assim em função de uma série de desvios que salientam as dificuldades e os limites do ato de narrar.

Retornos constante do locutor/narrador ao que acaba de dizer com a finalidade tanto de reforçar, atenuar, explicitar ou reformular suas palavras, são classificados pela retórica clássica como ferramentas discursivas que corroboram o desejo de clareza e exatidão daquele que fala. A discursividade que implica a figura aqui da epanortose conduz a uma extensão da frase que tem seu término adiado em virtude da construção de um sentido, o que, no âmbito da lógica retórica, visa 
à transparência, à clareza e à precisão. A singularidade do gesto narrativo de Elvira Vigna em $O$ que deu para fazer em história de amor repousa na subversão desta função. Se a epanortose admite o erro mas desde que haja correção afim de não romper a comunicação, o seu ampliamento para além do espaço frásico, bem como o seu acúmulo, criam um efeito contrário ao trilhado pela retórica. Os retornos constantes da narradora aparecem menos como correções do que rasuras que imprimem cortes sucessivos na cadeia da lógica linear do discurso, ora puxando seus freios, ora segmentando-o, ora postergando seu significado para nunca o afirmar completamente. Ao evocar a tentativa de inserção temporal de sua história, a narradora comenta:

Me parece um bom começo, trepadas no chuveiro. [...] mas não é nem certo eu falar sobre isso agora, de entrada, porque ainda não sei, nesse momento, como podem ser entendidas essa coisas daquela época [...] porque as coisas mudam. As coisas não mudam, justamente. Porque poderia contar a história de Arno, Rose, Gunther, Roger - e, em menor escala, da mulher de Gunter - no pós-guerra da década de 40, 50. [...] Entre uma e outra, uns vinte anos de diferença. $\mathrm{E}$ - acho eu aqui e agora, antes de começar, - bem poucas outras diferenças. Por exemplo, e ambas as histórias, nada de tão bombástico. Porque as coisas mudam, as coisas não mudam, mas bombástico definitivamente não é mais uma possibilidade. Masmo quando o foram. Ao contar, não mais o temos. Bombástico é, ja disse, o nine eleven. Bombástico, agora, só em inglês. Perdemos o bombástico, nós. Nosotros (VigNA, 2012, p.15).

Quanto mais ela tenta tapar as falhas da linguagem, mais buracos ela cava para finalmente se situar no espaçamento (ou na "espaciação") das incertezas que ela própria suscita. Retomando mais uma vez o incipit do romance aos trancos e barrancos:

E quero porque precisamos da história. Precisamos. [...] E é isto que eu quero/não quero [...]. Invenções modestas é bom que se saiba [...]. Invenções menores e parciais, vou avisando. Quase que não, as invenções. [...] e o que funciona: o contar apenas, como se fossa uma história. Mesmo quando não é. Ou quase que não. [...] no Guarujá, [...] poderia aperfeiçoar a história que quero contar e que não é bem uma história, mas duas. [...] e não sei o final. Ao começar, não sei como acabo, como ficarei, eu. É meu suspensinho particular. Este final que não sei qual vai ser, quando vier, se vier, será meu pagamento, aquilo que espero receber pela minha estada por lá. O "lá" que, sim, conheço. [...] meu pagamento será, assim espero, um quase ponto-final na minha história, a real, com Roger. [..] e é um quase ponto-final, e não um ponto-final inteiro, redondo, indissolúvel, perfeito, porque a história, por mais que eu (me) imponha uma Rose, uma Gunther e um Arno, há muito extintos, nunca poderá ser só minha. Só contada por mim. Dela meu controle é bem relativo. Pois me faltará sempre o conluio dos outros. Um "é assim" (VIGNA, 2012, p. 12-13). 
Este "lá" indefinido, o quase-ponto final tão almejado e nunca encontrado pela voz narrativa de $O$ que deu para fazer em história de amor, surge em Por escrito (2014) sob a forma de espaços marcados pela vacuidade e esvaziados de identidade: feiras comerciais, quartos de hóteis onde se multiplicam os mesmos lençóis e os mesmos televisores pregados nas paredes, sarjetas de ruas e, sobretudo, as salas de espera de aeroportos com ou sem pães de queijo, espaços desprovidos de temporalidade e espacialidade, recintos sem idas nem volta, esse lugar nenhum em que se situam personagens, voz e o próprio gesto narrativo. A vacuidade espacial a partir da qual se articula boa parte do romance, corresponde um espaçamento existencial que caracteriza narradora e em função do qual ela vê e é vista.

Integrada no vasto domínio daquilo que Genette (1972) chamou modo, a perspectiva narrativa é uma designação importada das artes plásticas para referir o conjunto dos procedimentos de focalização que contribuem para a estruturação do discurso narrativo. Comumente distinguem-se três tipos de focalização (interna, externa e omnisciente) as quais Elvira Vigna reserva um tratamento particular em Por Escrito. Nomeadamente, no que tange à sua especificidade "externa", àquela constituída, segundo os teóricos, pela restrita representação das caracerísticas superficiais, e materialmente observáveis, de uma personagem, de um espaço ou de certas ações. Afim de delimitar a informação diegética, a focalização externa decorreria sobretudo de um esforço do narrador em se referir de modo objetivo e desapaixonado aos eventos e personagens que integram sua história privando-a de um focalizador na origem do processo de referencialização. Os procedimentos de focalização externa presentes no incipt do romance Por escrito, e, em particular, na cena que descreve o ato sexual entre Molly e o marido de Dona Tereza, contradizem tal postulado.

A cena se insere na lógica de abertura do romance. A narradora acaba de chegar em Paris e, instalada em seu apartamento, imagina o encontro entre os dois amantes. Para além de suscitar o interesse do leitor, esta cena serve de via de acesso ao estabelecimento do programa e do contrato narrativos expondo os elementos principais do universo diegético: a caracterização das personagens (Molly, a narradora, Dona Tereza, seu marido), a localização espacial (Paris versus espaço interiorano), a temporalidade (presente de enunciação e passado distanciado) e os tipos de focalização, aqui determinantes na designação das instâncias e dos níveis narrativos. Em vez do tradicional movimento analéptico realizado através de uma instância subjetiva (homo/autodiegética) ou objetiva (heterodiegética) mediante proximidade (intradiegética) ou distanciamento (extradiegético) em relação ao fato diegético, a narradora opta por um sistema híbrido que a alusão à metafora cinematográfica vem salientar. Toda a cena é descrita através de duas fontes focalizadoras móveis que tanto se aproximam como se distanciam do evento narrado. Num primeiro momento uma câmera, levemente em contre-plongé, capta de maneira quase imparcial e mediante um plano geral os objetos e as personagens que compõe a cena: a cama, as colchas de cetim e de rendão cru, a almofada no chão, Molly e seu parceiro sexual visto de costas. 
A cama é grande, com duas colchas. Uma de cetim salmão, outra de rendão cru. A de rendão serve para manter a de cetim no lugar, para que não escorregue até o chão. Uma almofada de brocado que combina com o tom salmão também ajudaria a prender tudo no lugar, mas não tem nada no lugar. A almofada está no chão, as duas colchas estão emboladas. Sobre elas, Molly. Sobre Molly, um cara (VIGNA, 2014, p. 20).

A fixidez da câmera, o detalhismo do processo descritivo e a quase ausência de elementos de subjetivização conferem à cena uma certa neutralidade como se em sua apresentação/representação nenhuma mediação realizada a partir do ponto de vista de qualquer personagem particular da diégese pudesse ser detectada. A esta primeira cena contrapõe-se um segundo plano descritivo em que opera um desdobramento da fonte focalizadora. Câmera e instância narrativa passam então a atuar conjunta e independetemente na veiculação da informação diegética.

Se capricho, ponho uma cômoda de jacarandá por perto. Uma daquelas tigelas, não é tigela o nome. Gamela. Uma daquelas gamelas de madeira sobre a cômoda. Jaca, cajás, maracujás. Tudo bem amarelo. E o jajajaja na cuíca. Seria jajajajazizizijajaja se eu pudesse escrever zizizi assim no meio da cena. Fica só o jajaja. O cara se esforça. Molly não se esforça (VIGNA, 2014, p. 20).

Ao se apoderar do olhar da câmera, substituindo-se, parcialemente a ele, a narradora assume um papel no trecho descrito de mediadora sem, no entanto, privarse de um posicionamento externo graças ao qual ela observa, comenta, retroage os fatos evocados. Se tal posicionamento contrabalancea a autonomização hegemônica do ponto de vista externo, ela ocasiona um efeito de distanciamento e aproximação simultâneos próximos ao descrito pelo filosófoso Gilles Deleuze acerca da produção cinematográfica de Pasolini.

Para Deleuze, a subjetividade indireta livre de Pasolini é concomitante à emergência de uma "consciência-câmera" que transforma e reflete a visão do personagem em relação ao seu entorno. A "consciência-câmera" não se limita a uma mistura entre dois sujeitos de enunciação (o relator e o relatado). Ela atesta, antes, a co-existência de dois atos de "subjetivização" inseparáveis através de um translado permanente entre os polos objetivo e subjetivo: o da personagem em primeira pessoa em direção do polo externo e neutro e deste para a personagem colocandoa em cena e assegurando-lhe a existência (Deleuze, 1983, p. 106). Tal porosidade e movimentação verifica-se na cena do romance aqui descrita. Em Por Escrito o "estar-com-a-câmera" de que falava Deleuze mostra e deixa adivinhar. Ele conduz a diversas fontes focalizadoras, bem como anula as fronteiras que derterminavam as categorais espaço-temporais estanques.

Já fiz essa história antes. Quantas vezes. Já vi Molly nessa idade. Quantas vezes. Uma delas é num aeroporto. Nem lembro mais quando. Senta bem 
na minha frente. [...] Uma nova Molly. Toda uma nova leva de Mollys. Volto. Eu, a presa, eu, não ela, a prisioneira, presa na história, no sanduíche entre as colchas e o cara, entre o que não passa e o que não vem. Eu, a Molly. [...] E faz uns ahns. Vou precisar ter cuidado aqui. Como te (me) passar esses ahns. Que sim, conheço e por toda a minha vida, suas progressões e variações, e o que exatamente querem dizer. E os conheço porque nunca os escutei. (E é claro que esses primeiros ahns ainda não são os ahns definitivos, que ela vai assumir depois, são uns ahns experimentais, são a descoberta de som possível). (E agora me ocorre que também eles, por nunca terem sido escutados, são uma ausência de uma ausência e que, portanto, falo deles desde o começo, o meu começo, e o começo disso aqui). Molly faz os seus primeins ahns (VIGNA, 2014, p. 20-21).

A cena "original" invade o presente de enunciação ao passo que a narradora se projeta na cena descrita confundindo-se com sua personagem para finalmente distanciar-se dela, comentá-la e comentar o próprio gesto narrativo efetuado pela voz enunciadora e pela fonte focalizadora neutra (a câmera), ambas situadas num espaço/tempo indefinidos, móveis e instáveis. Em suma, ao multiplicar os campos de presença, o processo de focalização (externo e externo opacificado, segundo a nomenclatura cinematográfica) o texto multiplica as possibilidades de presentação e representação do fato diegético, fragilizando, no entanto, a posição do narrador e do leitor, que, desprovidos de um espaço/tempo fixos se inserem no espaçamento escavado pelo próprio gesto literário.

Na esteira do pensamento de Agamben (1995), a obra de Elvira Vigna compreende uma dimensão ética centrada no gesto, enquanto comunicação de uma comunicabilidade. Se como afirma o filósofo italiano, a linguagem já não tem mais nada a dizer, o gesto que lhe subjaz exibe o engajamento daquele que se inscreve nela e nela se perde. O mesmo deslize do "dizer" ao "mostrar" observa-se no universo romanesco de Elvira Vigna que confere ao gesto literário um lugar central no seu processo escritural. Não se trata mais aqui de comunicar algo pelo viés da linguagem, mas antes pôr em evidência o seu próprio meio de comunicação. O texto mostra e comenta os desvios provocados pela multiplicação dos jogos autocorretivos e das fontes focalizadoras. A perturbação, a correção, e até a extinção da enunciação confrontam o leitor e a realidade do próprio ato de narrar: o vazio deixado após os processos autocorretivos, o vazio dos "espaços nenhuns" que permeiam os romances, e, enfim, o olhar esvaziado das focalizações opaficadas. Ora é justamente neste espaço-espaçamento esvaziado que se opera o engajamento da voz autoral em relação ao gesto literário, à sua identidade e à alteridade a que ela se confrontra. O "écart" (desvio, espaçamento ou espaciação) constituiria, segundo o filósofo francês François Julien, a figuração (e não figura) da própria alteridade. Ele é fecundidade, na medida em que:

Pela distância aberta, ele [o desvio] permite um face a face recíproco de um pelo outro: onde se descobre a si mesmo no olhar do outro, a partir do outro, separando-se dele (JuLIEN, 2012, p. 33). 
Ou se preferirmos, nas palavras de Elvira Vigna:

Tenho muita clareza sobre o motivo de eu fazer literatura. Pretendo, com ela, tornar minhas as histórias que fui obrigada a viver. Só tem um jeito de elas se tornarem minhas: é passarem pelos outros. Essa tentativa se dá no "mundo comum", um termo da Hanna Arendt que designa o espaço das diferenças que me separam e me aproximam desse outro. É, portanto, um espaço da intersubjetividade, esse, onde minha literatura existe. Ou seja, para que ela se dê, é preciso que haja um outro, uma outra maneira, que não a minha, de viver a vida. Aí reconheço a minha como sendo minha. [...] A má notícia é que essa literatura - minha e de outros colegas do contemporâneo - é árdua. Não só para nós, os escritores que a propomos, mas também para esse outro, o leitor, que é convidado a participar daquilo que ainda não está pronto, que nunca fica pronto, daquilo que não só não tem um significado a oferecer como, pelo contrário, se declara falho, necessitado de sócios para sua ressignificação contínua. Esse compartilhar, esse admitir insuficiências e necessidades, a admissão de que precisamos da alteridade para viver, isso exige esforço. Alteridade vem de alterar. E alterar, principalmente alterar a si mesmo, dá um enorme trabalho (VIGNA, 2014).

\section{Referências}

Agamben, Giorgio. Moyens sans fins, Notes sur le politique. Paris : Ed. Rivages, 1995.

Collot, Michel. Pour une géographie littéraire. Paris : Corti, 2014.

Da MAta, Anderson. "Resenha de O que deu para fazer em matéria de história". O Globo, Prosa e Verso, 23 de Junho de 2012. Disponível em: https://blogs.oglobo. globo.com/prosa/post/resenha-de-que-deu-para-fazer-em-materia-de-historiade-amor-451844.html. Acesso em 3 maio 2021.

Deleuze, Gilles. L'image Mouvement. Paris: Minuit, 1983.

Genette, Gérard. Figures III. Paris : Editions du Seuil, 1972.

Julien, François. L'écart et l'entre. Léçon inaugurale de la Chaire sur l'altérité. Paris : Galillée, 2012.

Ricoevr, Paul. Temps et récit. 2. La configuration dans le récit de fiction. Paris: Seuil, 1984 .

VignA, Elvira. "Em busca de um narrador", 2011. Disponível em: http: //etudeslusophones.blogspot.com/2011/11/um-dedo-de-prosa-com-elvira-vigna.

html. Acesso em: 20 abril 2020.

VignA, Elvira. O que deu para fazer em matéria de história de amor. São Paulo: Companhia das Letras, (2012).

Vigna, Elvira. "Literatura e experiência", 2014. Disponível em : http://vigna.com. $\mathrm{br} /$ divexperiencia/. Acesso em: $1^{\circ}$ agosto 2017.

Vigna, Elvira . Por escrito. São Paulo: Companhia das Letras, 2014. 
Recebido em 23 de abril de 2020.

Aprovado em 5 de agosto de 2020.

\section{Resumo}

\section{Espaçamentos em Elvira Vigna}

\section{Leonardo Tonus}

O presente trabalho tem por objetivo indagar como a literatura brasileira contemporânea tem pensado e reavaliado a espacilidade de seus narradores. A partir do conceito de "espaçamento" veremos de que maneira o distanciamento emocional e cognitivo imposto às vozes autorais nos romances $O$ que deu para fazer em matéria de história de amor (2012) e Por escrito (2014) da escritora Elvira Vigna colocam em xeque a artificialidade da ficção, apontando ao mesmo tempo, para uma dimensão ética do gesto literário.

Palavras-chave: Elvira Vigna, écart, espaçamento, narrador. 